This item was submitted to Loughborough's Research Repository by the author.

Items in Figshare are protected by copyright, with all rights reserved, unless otherwise indicated.

\title{
Scope for domestic appliance dynamic demand side management
}

PLEASE CITE THE PUBLISHED VERSION

https://doi.org/10.1049/icp.2021.0959

PUBLISHER

IET

VERSION

AM (Accepted Manuscript)

PUBLISHER STATEMENT

This paper was accepted for publication in The 10th International Conference on Power Electronics, Machines and Drives (PEMD 2020) and the definitive published version is available at https://doi.org/10.1049/icp.2021.0959.

\section{LICENCE}

CC BY-NC-ND 4.0

\section{REPOSITORY RECORD}

Chinyemba, Tinashe, Farhad Anvari-Azar, and Dani Strickland. 2021. "Scope for Domestic Appliance Dynamic Demand Side Management”. Loughborough University. https://hdl.handle.net/2134/14188850.v1. 


\title{
SCOPE FOR DOMESTIC APPLIANCE DYNAMIC DEMAND SIDE MANAGEMENT \\ Tinashe Chinyemba ${ }^{1}$, Farhad Anvari-Azar ${ }^{2}$, Dani Strickland ${ }^{*}$
}

\author{
${ }^{1}$ Wolfson School ,Loughborough University, Loughborough, UK \\ ${ }^{2}$ Green Frog Power, Gorsey Lane, Birmingham, UK \\ *d.strickland@lboro.ac.uk
}

Keywords: DSR, DSM, FREQUENCY RESPONSE, DOMESTIC APPLIANCE CONTROL, MARKETS

\begin{abstract}
It is expected that the future UK's grid inertia will reduce as the UK moves towards decarbonisation. The consequence is that National Grid may have to have to increase its spending on primary frequency responses, to keep the frequency within limits. There is however, potential for National Grid to reduce this cost with the assistance of a dynamic domestic Demand Side Management schemes. This paper considers how domestic appliances may be utilised to help with frequency response. This paper looks at the potential size of a domestic appliance service using a droop based scheme to participate in dynamic Demand Side Management for frequency response and determines the impact of this on frequency response costs.
\end{abstract}

\section{Introduction}

The control of the grid frequency is a balancing act between generation and demand. Generators have an inherent inertia associated with their operation which assists with this. Rotating load also helps to contribute to grid inertia albeit on a much smaller scale which may be typically modelled as a change in load with frequency as shown in equation (1). The increase in power electronic converters have acted to reduce the grid inertia of both generation and loads. This has an impact on the market for frequency control services.

$$
D=\frac{\Delta P_{L(\text { freq })}}{\Delta \omega}
$$

In the UK, National Grid use a variety of balancing services to control the frequency including STOR and Firm Frequency Response (FFR) also known as Primary, Secondary and High response modes [1]. This FFR response can be static (the generator is either on or off based on a threshold and must respond within 30s) or dynamic - the generator continually changes output to follow the frequency and must respond within 10s. The minimum participation size of a holding is currently $1 \mathrm{MW}$ which may be met through an aggregated service [2]. Some of the frequency response service is undertaken using Demand Side Response (DSR) also sometimes referred to as Demand Side Management (DSM). The majority of DSR is done by switching loads on and off in response to the frequency. In addition to turning the load on and off (similar to a static response), some attempts have been proposed in previously published literature to control loads in a dynamic response mode.

Control attempts have been made to directly control water heaters by using "ripple" control technology, such as turning water heaters on and off with frequency [3]. An alternative control strategy has been proposed in [4], based on a house with multiple controllable loads that have a priority rating. The control scheme considers preference settings and the loads are turned on and off in order such that there are marked setpoints with frequency deviation rather than an on/off approach. Reference [5] proposes a control strategy for DSM that temporarily prohibits the turn on of high power appliances that are not already in use. This reduces the number peaks on the load profile. In addition to turning the devices on and off, some research has looked at changing the setpoints. Ciapessoni et al [6] undertook peak clipping with domestic fridges and heaters, by temporarily changing their setpoints. Reference [7] explored the different variations of controller's configurations of commercial Heating, Ventilation and Air-Conditioning (HVAC) loads, for the purposes of frequency regulation. The power consumptions of HVAC systems can be modified by either adjusting fan speed by controlling the variable frequency drive and/or applying a mass/pressure flow offset and applying a thermostat set offset.

Reference [8] - [9] have published simulations undertaken for the use of DSM to provide FFR. [8] investigated the impact of DSR in FFR, the methodology proposed the use of domestic thermostatic devices such as domestic water heaters and cooling loads. They are considered flexible due to their inert thermal inertia. The thermostat set point changes in response to the frequency. Reference [9] looked into reducing load to be used within FFR, this used a droop-based demand response on a DC load. The PMW controlled synchronous rectifier allowed for the load to be adjusted appropriately rather than just turning this load on/off. The PWM controlled rectifier allowed for more flexibility in load. The Pacific Northwest National Laboratory in America conducted a demonstration project for an autonomous underfrequency controller called the Grid Friendly Appliance (GFA) [10]. The controller was configured to observe the frequency (nominal value $60 \mathrm{~Hz}$ ) and when the frequency fell below $59.95 \mathrm{~Hz}$. The GFA controller would then request for the connected appliance to reduce its load. The project used residential clothes dryers that were manufactured for the project and retro fitted water heaters. The cost of the GFA 
was approximately $\$ 44$. This is a significant cost to implement across a range of domestic products and would be unlikely to be feasible in practice.

This paper also looks at reducing load in a domestic consumer environment as a method of reducing the costs of balancing to National Grid and ultimately the consumer. The paper uses an alternative approach to those already published. This paper investigates if there is sufficient scope of magnitude to adjust ac loads dynamically in a similar manner to reference [9] by experimentally testing appliances to understand what change in power is possible with a change in frequency. Historically it has been assumed that a $3 \%$ variation in voltage on the grid produces a 5\% demand reduction. However, operation Juniper in the UK in 2013 showed that reducing the voltage at the primary substations only showed a load reduction of $1.5 \%$ [11]. As some of these loads are constant power, reducing the voltage acts to increase the current and so the split between loads which can be used for response and those that can't results in figures that are lower than expected. This paper splits out the constant power loads and targets only those loads that show reduced power with voltage which can then be used to reduce power consumption with frequency.

Section 2 presents the methodology used to understand the available load reduction that might be available. Section 3 presents the results from a range of load types. Section 4 quantifies what this might mean for National Grid in terms of cost reduction of FFR services.

\section{Experimental methodology}

To work out the scope for reducing domestic load with decreasing frequency to help meet dynamic response services it is necessary to understand what level of power variation is available from different loads at different voltage and frequency levels. Only those loads that offer the chance to manipulate the power with frequency in the correct manner will be potentially available as a service. The most practical means of adjusting the load with frequency is to choose loads that have an operational envelop independent of frequency but that then offer the chance to reduce the power drawn by manipulating the input voltage. It was decided not to use an appliance which would need to operate at a higher power level in order to provide these services as this would increase electricity consumption and negatively impact the customer.

Fig. 1 shows the single line diagram of the setup used to investigate how load changes with respect to voltage and frequency, while Fig. 2 shows a photo of the test set up.

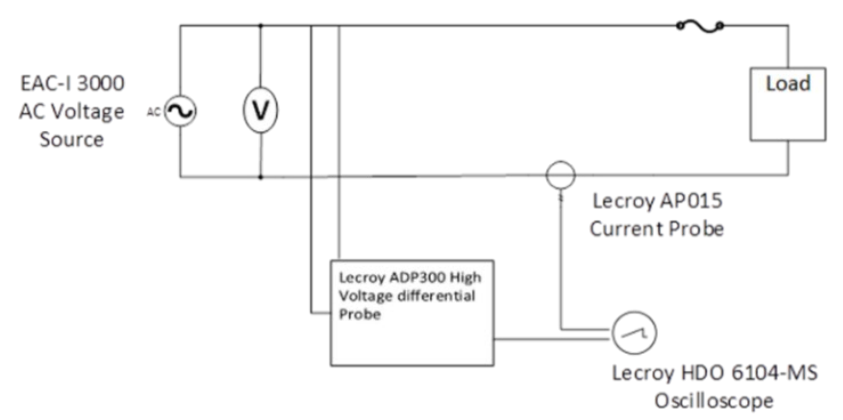

Fig. 1. Test Schematic Set Up

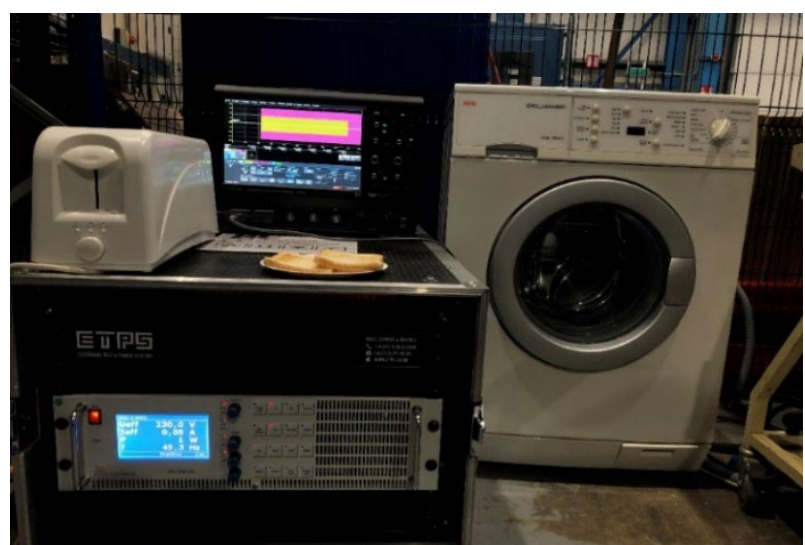

Fig. 2. Test Rig photo

In the UK, the voltage standard is 230 volts $-6 \%,+10 \%$. This gives an allowed voltage range of 216.2 volts to 253.0 volts. There is therefore more scope to provide frequency response when the voltage is $253.0 \mathrm{~V}$ than when it is $216.2 \mathrm{~V}$. At the nominal value of $230 \mathrm{~V}$, the scope for droop control is approximately:

$$
\text { droop }=\frac{\Delta P}{P_{r}} \times 100
$$

Where

droop is the $\%$ of power available for frequency response $\Delta P$ is the change in power between nominal voltage and $-6 \%$ $P_{r}$ is the rated power of the device

\section{Experimental Results}

The domestic devices that were tested included a kettle, toaster, iron and sandwich press, along with fridges, washing machines and other more complex loads. As part of this testing overall performance was compared in conjunction with the voltage, current and power measurements.

\subsection{Kettle}

A Cookworks 12106 kettle was tested between $45 \mathrm{~Hz}$ and $55 \mathrm{~Hz}$, for a voltage range between $220 \mathrm{~V}$ and $240 \mathrm{~V}$. The kettle operates at unity power factor and is on continuously. During the course of the experiments the power factor remained at unity. Results in Fig. 3 indicate that as the voltage drops so does the power consumption, this makes the kettle a viable domestic appliance for DSM. However the time for the kettle to boil increased. $7 \%$ droop is available at nominal voltage.

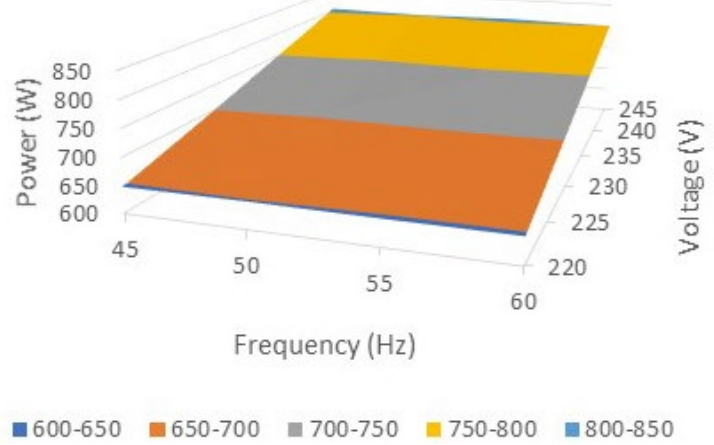

Fig. 3. Kettle Power Variation with Frequency and Voltage 


\subsection{Iron}

A 043269 Sainsbury's own brand iron was tested between $45 \mathrm{~Hz}$ and $55 \mathrm{~Hz}$ with a voltage range between $220 \mathrm{~V}$ and $240 \mathrm{~V}$. The iron operates in conjunction with a thermostatic switch which turns the heating element on and off with temperature. The iron is unaffected by the variations in frequency. The iron is active approximately $20 \%$ of the time when the iron is on. The power consumption variation when the iron is on is shown in Fig. 4. At nominal voltage 8\% droop in power is available.

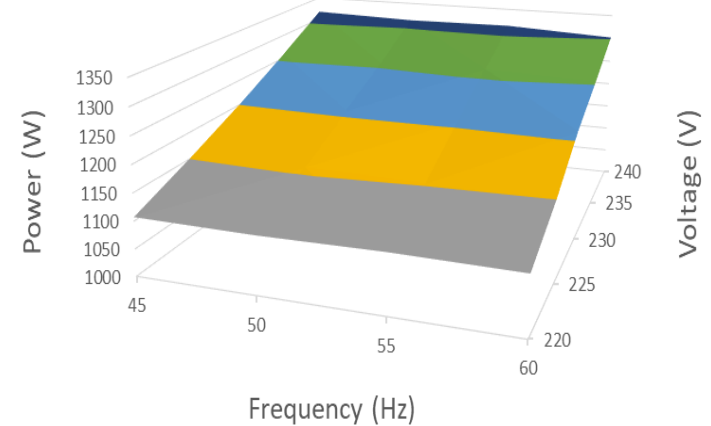

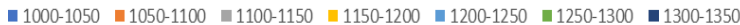

Fig. 4. Iron Power Variation with Frequency and Voltage

\subsection{Sandwich Toastie}

A SM09 Tesco own brand sandwich toastie maker was tested between $45 \mathrm{~Hz}$ and $55 \mathrm{~Hz}$, for a voltage range between $220 \mathrm{~V}$ and $240 \mathrm{~V}$. The sandwich toastie maker operated at unity power factor and operates in conjunction with a thermal switch which turns the heating element on and off with temperature. During the course of the experiments the power factor remained at unity. Results in Fig. 5 indicate that as voltage reduces, so does power and is independent of frequency. The droop available at $230 \mathrm{~V}$ nominal is around $12 \%$.

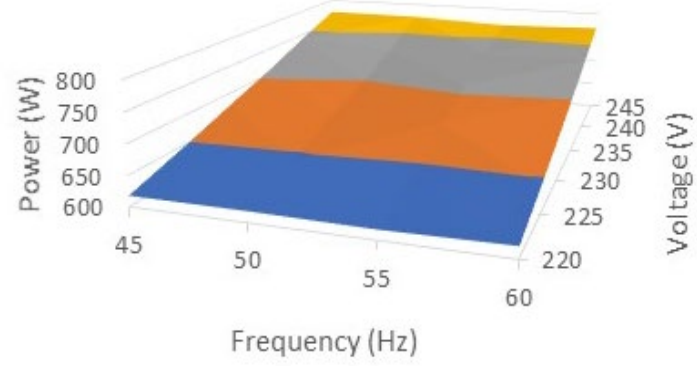

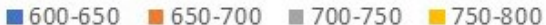

Fig. 5. Sandwich Toastie Power Variation with Frequency and Voltage

\subsection{Toaster}

A WMTTW4S002 Wm Morrisons own brand toaster was tested between $45 \mathrm{~Hz}$ and $55 \mathrm{~Hz}$. Each frequency was tested with a range of voltages between $220 \mathrm{~V}$ and $245 \mathrm{~V}$. Results shown in Fig. 6 indicate that as the voltage decreased so did the power consumption. The frequency did not have an effect on the power consumption of the toaster.

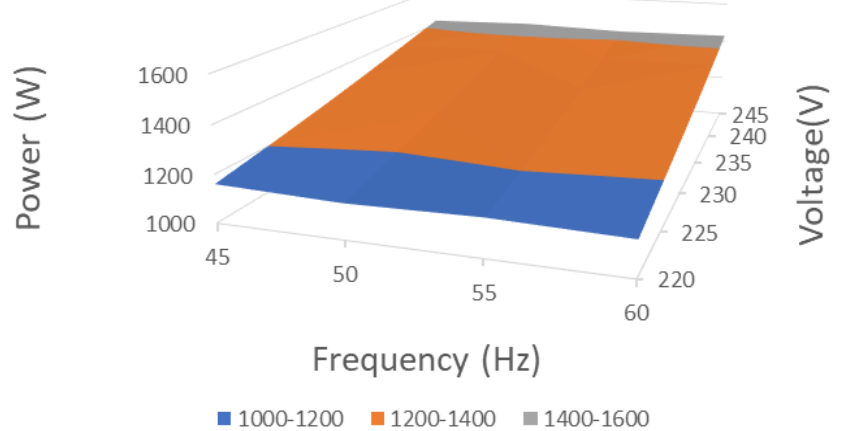

Fig. 6. Toaster Power Variation with Frequency and Voltage A control test used was to look at the impact on the toast colour for a fixed setting under the different conditions. These showed that frequency had little impact, but the reduction in voltage resulted in less power to the toaster and therefore a lighter toast as seen in Fig. 7. There is approximately $11 \%$ droop at nominal frequency.

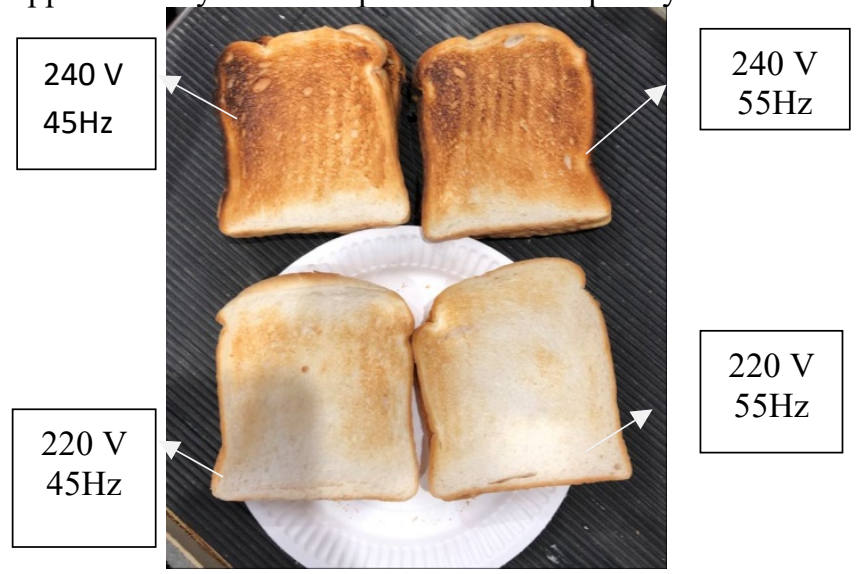

Fig. 7. Toast produced under different conditions

\subsection{Load Availability for DSR}

The experimental results show that the kettle, iron, toaster and sandwich toaster, have scope to participate in a droopbased DSM scheme. Motor based appliances such as fridges and washing machines were not suitable. Table 1 lists other domestic loads that can be used for DSM within the UK. In all these devices, power consumption varies with voltage and performance is independent of frequency.

However, it is not just a case of what power is available to participate, but also when it is available. Data from the National Statistics in Fig. 8 shows the approximate number of houses in the UK [12]. Fig. 9 uses the CREST load model [13] which calculates the probability that an appliance is on based on results from a time of use study to estimate resistive load. The probability that a resistive based load is on is multiplied by the number of houses and average power consumption to get a minute resolution of the total resistive based load in the system in each minute. As expected, the highest peak occurs during the evening period. If it is assumed that this load has a droop capability of $8 \%$ available, based on the experimental values, this equates to a theoretical peak load reduction of $1120 \mathrm{MW}$. 
Table 1 Domestic Loads

\begin{tabular}{|c|c|c|c|c|c|}
\hline 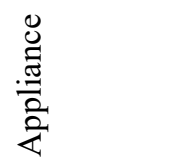 & 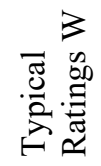 & $\stackrel{\mathscr{E}}{\Xi}$ & 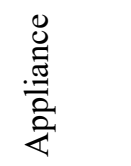 & 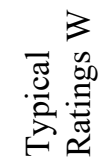 & 异 \\
\hline Kettle & $\begin{array}{l}2200- \\
3000\end{array}$ & Min & $\begin{array}{l}\text { Steam } \\
\text { Cleaner }\end{array}$ & 2000 & $\mathrm{Hr}$ \\
\hline Toasters & $\begin{array}{l}700- \\
1500\end{array}$ & Min & $\begin{array}{l}\text { Laptop } \\
\text { Charger }\end{array}$ & $45-85$ & $\mathrm{Hr}$ \\
\hline Deep fryer & 1200 & Min & $\begin{array}{l}\text { Electric } \\
\text { Hob }\end{array}$ & $\begin{array}{l}1000- \\
2000\end{array}$ & $\mathrm{Hr}$ \\
\hline $\begin{array}{l}\text { Oil filled } \\
\text { Radiator }\end{array}$ & $\begin{array}{l}1500- \\
2500\end{array}$ & $\mathrm{Hr}$ & $\begin{array}{l}\text { Electric } \\
\text { Shower }\end{array}$ & $\begin{array}{l}7000- \\
10500\end{array}$ & Min \\
\hline $\begin{array}{l}\text { Instant Hot } \\
\text { Tap }\end{array}$ & 1430 & Min & $\begin{array}{l}\text { Power } \\
\text { Shower }\end{array}$ & $\begin{array}{l}8500- \\
10500\end{array}$ & Min \\
\hline $\begin{array}{l}\text { Dish } \\
\text { washer }\end{array}$ & $\begin{array}{l}1050- \\
1500\end{array}$ & $\mathrm{Hr}$ & $\begin{array}{l}\text { Slow } \\
\text { Cooker }\end{array}$ & 250 & $\mathrm{Hr}$ \\
\hline Iron & $\begin{array}{l}1000- \\
1800\end{array}$ & Min & $\begin{array}{l}\text { Electric } \\
\text { Oven }\end{array}$ & $\begin{array}{l}2000- \\
2200\end{array}$ & $\mathrm{Hr}$ \\
\hline Towel Rail & $\begin{array}{l}250- \\
400\end{array}$ & $\mathrm{Hr}$ & $\begin{array}{l}\text { Rice } \\
\text { Cooker }\end{array}$ & 700 & $\mathrm{Hr}$ \\
\hline ir Fryer & 1400 & Min & $\begin{array}{l}\text { Deep } \\
\text { Fryer }\end{array}$ & 1800 & Min \\
\hline $\begin{array}{l}\text { Sandwich } \\
\text { and Panni } \\
\text { Press }\end{array}$ & $\begin{array}{l}1000- \\
2000\end{array}$ & Min & $\begin{array}{l}\text { Crepe } \\
\text { Maker }\end{array}$ & 1000 & Min \\
\hline
\end{tabular}

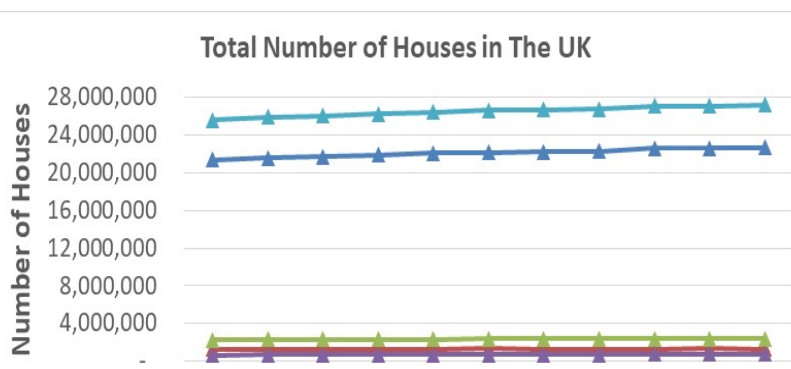

20072008200920102011201220132014201520162017

Calender Years

$₫$ England (Total) $₫$ Wales $₫$ Scotland $₫$ Northern Ireland $₫$ UK (Total)

Fig. 8. Total Number of Houses in The UK

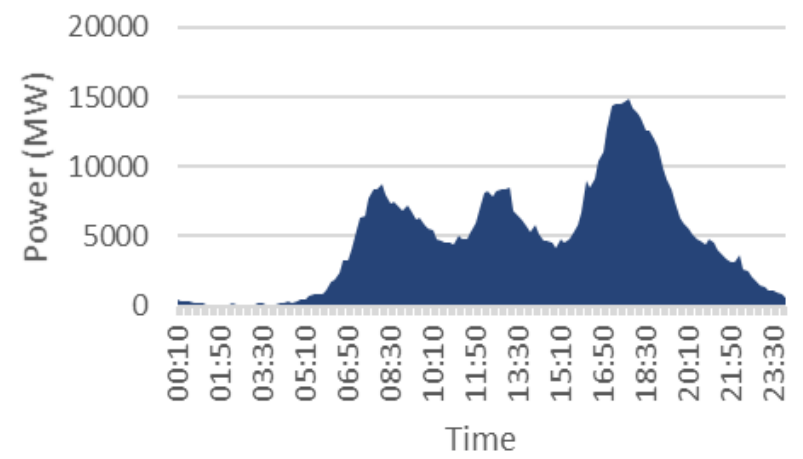

Fig. 9. Power Probability Distribution of Resistive based Domestic Appliances

\section{Frequency Response Services}

FFR frequency services are expensive and total expenditure on commercial frequency response was estimated as $>£ 70$ million in 2018 found by checking the contracted frequency each month. The faster the response the more expensive it is to purchase. Fig. 10 shows the accepted, availability prices for dynamic and non-dynamic years between APR-15 and JAN-21 from ELEXON[14]. In general, dynamic services were about four times more expensive. FFR dynamic services are expected to detect a frequency event within $2 \mathrm{~s}$ and ramp up to full output within $10 \mathrm{~s}$, while the figure for non-dynamic is $30 \mathrm{~s}$. The prices indicate that it is around 5 times more expensive to purchase dynamic response compared to static response. The contracted dynamic service is larger than the non-dynamic service as shown in Fig. 11. If the proportion of dynamic to non-dynamic service can be altered or reduced there could be good financial savings.

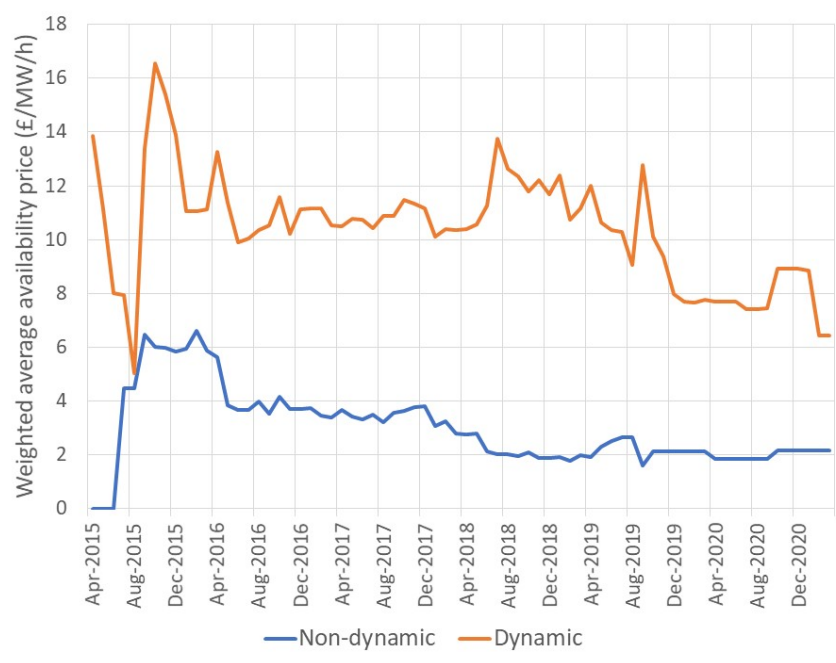

Fig. 10. Average accepted FFR weighted average availability price 2015

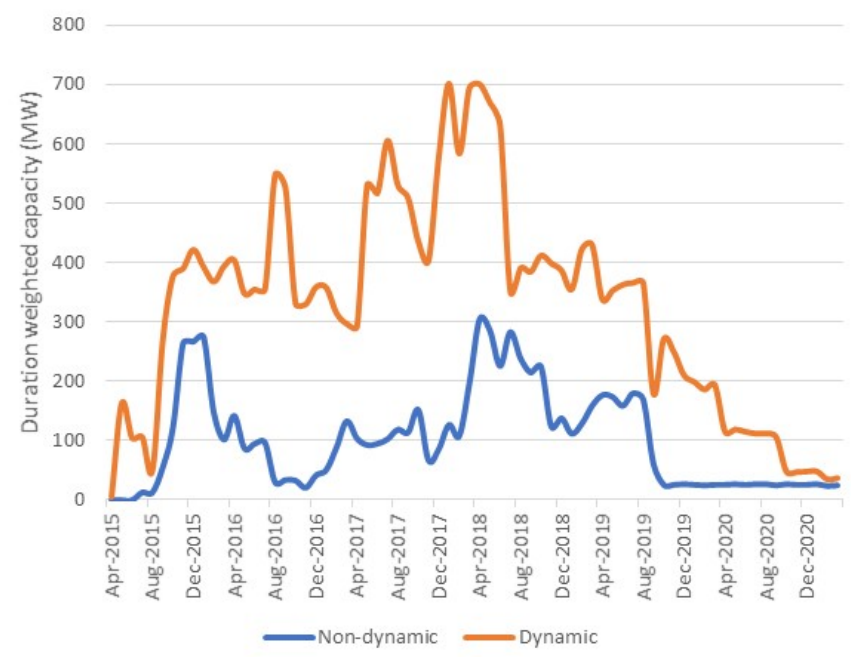

Fig. 11. Contracted volume of dynamic and non-dynamic frequency response since 2015 
This paper modifies the methodology presented in references [15-16] and calculates the change in frequency at different inertias for a $1 \mathrm{GW}$ step change in load to understand the effect of loss of infeed due to a significant event. Equation (3) is used to model the frequency:

$$
\frac{d f}{d t}=\frac{P_{\text {in }}-P_{\text {out }}}{2 S H} f=\frac{\Delta P}{2 I} f
$$

Where

$P_{\text {in }}$ is the active power input to the power system (MW)

$P_{\text {out }}$ is the active power output to the power system (MW)

$\Delta P$ is the active power imbalance (MW)

$\mathrm{S}$ is the apparent power rating of the machines connected to the power system (MVA)

$\mathrm{H}$ is the inertia constant connected to the power system (s)

I is the system Inertia (MVA.s)

$\mathrm{f}$ is the system frequency $(\mathrm{Hz})$

Equation (3) is a differential equation describing the change in frequency with time which can be solved using numerical techniques, in this case Euler's Forward method implemented in Matlab 2018b using the method in Fig. 12. The key difference in this paper compared to previous work is the change in power that would result from the use of an aggregated dynamically responsive load that is represented with a frequency droop characteristic, D, as defined in equation (1).

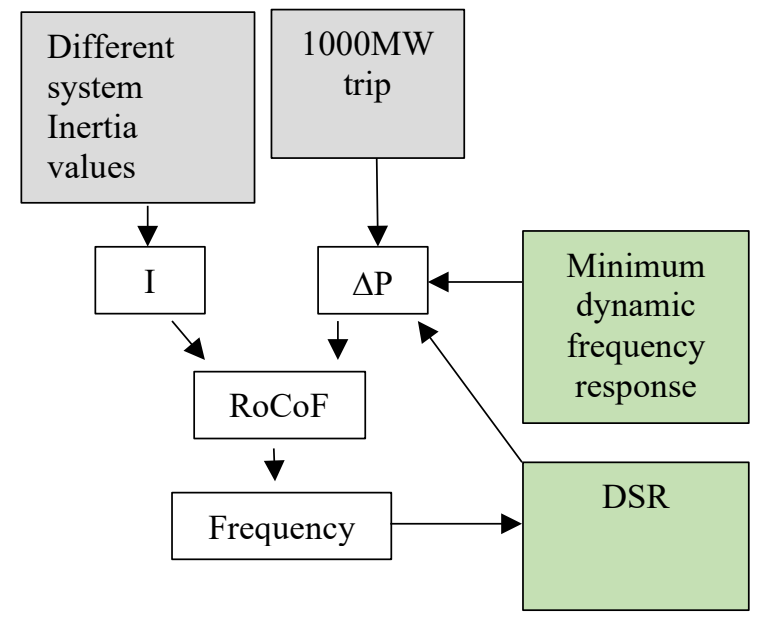

Fig. 12. Functional Frequency Calculation Model

The objectives of the simulations are to analyse and quantify the required level of primary response for four different scenarios of load response for a range of grid inertias from 160,000 MVA.s to 360,000 MVA.s. The following assumptions have been made.

1. Primary Response occurs with a 2 s detection and ramping to full power within $10 \mathrm{~s}$.

2. An event of a $1000 \mathrm{MW}$ interconnector trip

3. The frequency does not fall below $49.2 \mathrm{~Hz}$ and the calculated ROCOF does not exceed $0.5 \mathrm{~Hz} / \mathrm{s}$

Four different scenarios for load response have been considered;
The load is reduced at a fixed droop rate of $4 \%$ or $8 \%$ if the frequency drops below $50 \mathrm{~Hz}$ and the load is reduced at $4 \%$ or $8 \%$ if the frequency is below $50.5 \mathrm{~Hz}$ as shown in Fig. 13 .

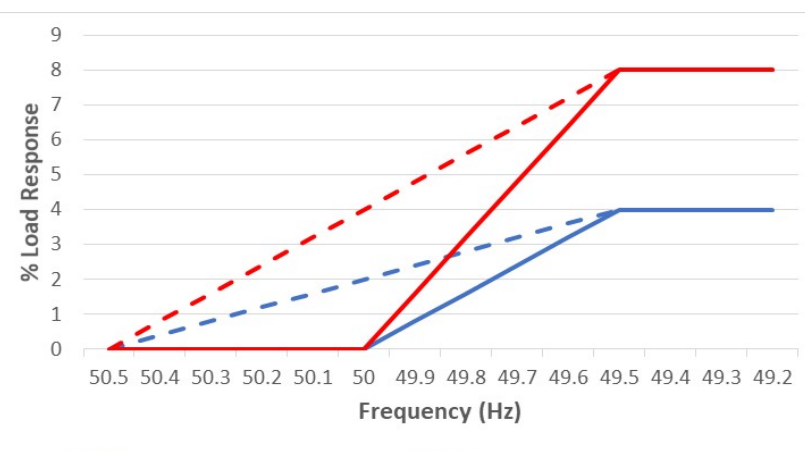

- Droop from at $50.54 \%$ droop rated load
Droop from at $50 \mathrm{~Hz} 8 \%$ rated load
Droop from at $50 \mathrm{~Hz} 4 \%$ rated load

Fig. 13 Load Response Scenarios

Fig. 14 shows the frequency in the event of a $1 \mathrm{GW}$ loss of generation at peak load with a low inertia and $300 \mathrm{MW}$ of primary response. The response from the demand at $8 \%$ droop is sufficient to significantly limit the frequency drop, while that at $4 \%$ shows a reduction of frequency and highlights the need to maintain some additional primary response. The minimum primary response required at each inertia for each scenario is shown in Fig. 15. To guarantee that the frequency won't drop below $49.2 \mathrm{~Hz}$ with an extremely low grid inertia, $410 \mathrm{MW}$ of holding reserve is required with a $4 \%$ droop.

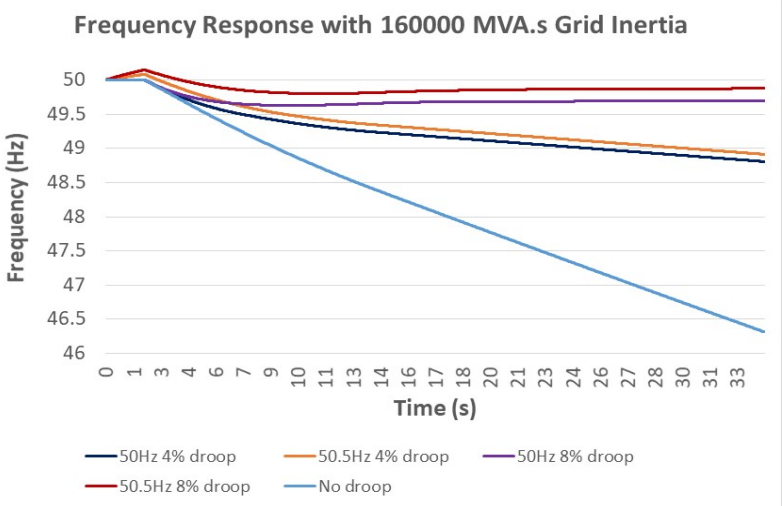

Fig. 14 Frequency Response for an inertia of 160000 MVA.s

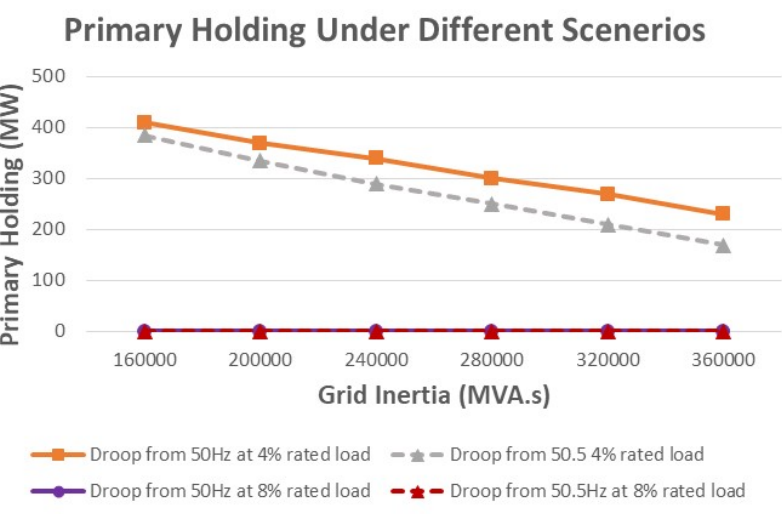

Fig. 15. Primary Holding under two different scenarios 
The implementation of a DSR scheme would reduce the requirement to operate at current levels of primary reserve opening the door to slower responding services which could be potentially cheaper. Cost indications indicate that (excluding mandatory FFR) reducing the commercial primary dynamic response by $400 \mathrm{MW}$ and increasing the level of secondary response to compensate for this would result in savings of around $£ 7.30$ per $\mathrm{MW} / \mathrm{h}$ availability payment (average dynamic - non-dynamic weighted average cost from Fig. 10) giving a potential saving of $£ 25 \mathrm{~m}$ per year.

If these savings could be extended for a period of 10 years, National Grid will save a total of $£ 250 \mathrm{~m}$. If a droop-based scheme was to be implemented in every household on up to 4 devices. Then a load reduction strategy would have to cost $<$ $£ 2.50$ per device to be effective.

\section{Conclusion}

As the UK moves towards decarbonisation, the inertia of the UK grid is likely to decrease. Consequently, if nothing else changes, National Grid may have to procure more primary dynamic response to keep the frequency within the limits. This paper has established that by using a droop based DSR scheme for controlling resistive based domestic devices such as a toaster, iron, sandwich toastie maker and kettle, there could be a potential of up to $1120 \mathrm{MW}$ of power that could be used as a buffer to alleviate the need for primary FFR services, opening the door to slower and cheaper secondary FFR services. This scheme has shown that it can adequately curtail the frequency for at least 30 seconds, until the secondary FFR is available. Initially costing has resulted in a target figure of $£ 2.50$ per load controlling device in order to be cost effective. This is significantly lower than previously published schemes and will be challenging to meet.

Future work will aim to implement such a device in hardware at the cost target price.

\section{Acknowledgements}

The authors would like to acknowledge the help provided by ETPS Ltd for their help purchasing the voltage source.

\section{References}

[1] National Grid Electricity System Operator, "Future requirement for Balancing Services," National Grid Electricity System Operator. [Online]. Available: https://www.nationalgrideso.com/sites/eso/files/documents/R equirements Report 2016.pdf. [Accessed: 14-Mar-2019].

[2] N. Gargov and J. Sun, "Technical Guidance and Testing Procedure for Static and Dynamic Demand Response and Battery Storage Providers of Frequency Balancing," National Grid, 2015. [Online]. Available: https://www.nationalgrid.com/sites/default/files/documents/D SR Battery Storage Test Procedure for Frequency Response.pdf. [Accessed: 02-Nov-2018].

[3] N. K. C. Nair, R. Nayagam, and R. Francis, "New Zealand utility experiences with Demand Side Management," IEEE Power Energy Soc. 2008 Gen. Meet. Convers. Deliv. Electr. Energy 21st Century, PES, pp. 1-5, 2008.
[4] R. Mehta, P. Verma, and D. Srinivasan, "Smart Load Control Strategy for Residential Demand Side Management," 2018 IEEE Innovative Smart Grid Technologies -Asia (ISGT Asia), 2018.

[5] N. Zhang, L. Ochoa, and D. Kirschen, "Investigating the Impact of Demand Side Management on Residential Customers", 2011, 2nd IEEE PES International Conference and Exhibition on Innovative Smart Grid Technologies.

[6] E. Ciapessoni, D. Cirio, and S. Massucco, "Demand Side Response for Frequency in a Regional Power System.”, 2015 International Conference on Clean Electrical Power (ICCEP) [7] I. Beil, I. Hiskens, and S. Backhaus, "Frequency Regulation from Commercial Building HVAC Demand Response," Proceedings of the IEEE, 2016.

[8] H. W. Qazi, D. J. Burke, and D. Flynn, "Challenges in Utilisation of Demand Side Response for Operating Reserve Provision," IEEE PES Innovative Smart Grid Technologies, Europe, 2014.

[9] A. Elrayyah, "Droop Based Demand Response for Power Systems Management," 2015 First Workshop on Smart Grid and Renewable Energy (SGRE), 2015.

[10] D. Hammerstrom et al., "Pacific Northwest Gridwise Testbed Demonstration Projects: Part 2. GridFriendly Appliances project," 2007.

[11] Ian Elders, "Flexible Networks for a Low Carbon Future" [Online] Available: https://www.spenergynetworks.co.uk/userfiles/file/Technical Note_on_Modelling_of_Load_45.pdf [Accessed: 16 Dec 2019]

[12] Office For National Statistics, "Total Number Of Households by Region and Country of the UK 1996 to 2017." Available: https://www.ons.gov.uk/peoplepopulationandcommunity/birt hsdeathsandmarriages/families/adhocs/005374totalnumberof householdsbyregionandcountryoftheuk1996to2015.

[Accessed:22 Nov 2019]

[13] Eoghan McKenna and Murray Thomson. "Highresolution stochastic integrated thermal-electrical domestic demand model". Applied Energy, 2016, 165:445

[14] Elexon website, https://www.elexon.co.uk/ [Accessed: 22 Nov 2019]

[15] K. Forkasiewicz, M. Coldwell, A. Cross, and D. Strickland, "Meeting Frequency Response Requirements with Uncertain System Inertia - a UK perspective," 2016 IEEE Int. Conf. Renew. Energy Res. Appl., 2016.

[16] Alexander D. Cooke, Kane Forkasiewicz, Dani Strickland, "Energy Storage for Enhanced Frequency Response Services,” 2017 52nd Int. Univ. Power Eng. Conf., 2017. 